\title{
Chapter 17 \\ Learning Through \\ Reflection-Enhancing Culturally \\ Proficient Learning Communities \\ in Midwifery Practice and Education: \\ An Experience-Based Learning Journey \\ in London, UK
}

\author{
Penny Haora
}

\section{Introduction}

This reflective narrative shares an experience of immersion at the highly political "intersectional" coalface of gendered, class and racially based maternity services research, practice and learning in London, UK. I initially set out to apply Levin \& Greenwoods' ( 2001, p. 103) "pragmatic action research" approach to transform a small component of universities and health services into learning communities. This was to be achieved through the introduction of a reflective cultural competence assessment tool. However, I encountered multiple resistances and was unable to introduce that tool. Instead, utilising Brookfield's (1995) critical lenses, I witnessed "prestige hierarchies" (Napier et al., 2014, pp. 1608-9), persistent deficit discourses and institutional racism; and privileged "white" educational structures that continued to support those practices, while simultaneously producing rhetoric of inclusion (University of East London, 2015). Transformative learning (Mezirow, 1997) was an explicit goal to be achieved within the learning experiences of students, and a goal of the active learning ideals of "learning by doing", role modelling and reflective learning, recognised in various fora. However, personal reflections on my own experience found that the goal of transformation was only relevant to the "student other", while within the academy, there was little opportunity to breach "professorial authority" (Levin \& Greenwood, 2001, p. xxxiv). Following Betancourt, Green, Carrillo, and AnanehFirempong (2003), I proposed using tools that were relevant to clinical practice, to support reflective learning at both individual and institutional levels, in pursuit of cultural proficiency (Lindsey, Nuri-Robins, \& Terrell, 2009). I offered a basic logic

P. Haora $(\varangle)$

National Centre for Immunisation Research and Surveillance, Westmead, NSW, Australia

e-mail: Penny.Haora@health.nsw.gov.au

J. Frawley et al. (eds.), Cultural Competence and the Higher Education Sector, https://doi.org/10.1007/978-981-15-5362-2_17 
model asserting that safe care spaces for women clients within maternity services must be preceded by safe learning spaces for midwives (staff) and students. Wikberg, Eriksson, and Bondas (2014) argued that culturally competent health services are a core component of "caring". They asserted that an expectation of care is universal when accessing health services. Poorer health outcomes for women from minority ethnicities within the UK (Hayes, Enohumah, \& McCaul, 2011) may be related to differences in health care-seeking behaviour but clearly that is also associated with experiences of care. Political will, cultural humility (Sreenivas, Cohen, MaganaValladares, \& Walker, 2015) and a partnership approach are essential, I argue, for sustained change and progress in both practice and educational contexts.

\section{Action Research Background and Context: The “Classroom" and Learning Philosophy}

While employed as a full-time university-based, service-embedded researcher in London, UK, from 2014 to 2017, I also held a small teaching role within the research programme. The research programme aimed to improve equity in birthing outcomes for women and families in East/North East London. This was a multi-site collaboration focusing on antenatal care (ANC), funded by a major UK health research funder, with a large National Health Service (NHS) Trust as the "host".

The maternity services research project I led involved implementation of an innovation, where we were developing and trialling a locally appropriate model of groupbased ANC. This model differed from standard care in several key areas that it is appropriate to outline here, due to their relevance to the action research (AR) project to be described in this chapter. The ANC model recognised "women as partners" in their pregnancy care and general well-being, by encouraging and actively seeking to empower women to voice their experiences and "knowledge" within a safe group space. The model also recognised the value of supportive relationships (Sandall et al., 2016), aiming to facilitate these during the transition to parenthood through enhancing "learning communities" (Levin \& Greenwood, 2001).

The same values and principles were recognised and reflected in relevant local and national strategic directions and professional standards; for example, in the University's Strategy for Closing the Attainment Gap (University of East London, 2015), the Higher Education Academy's “evidence-informed principles for effective pedagogies" (HEA, 2009) and the UK Professional Standards Framework (HEA, 2011) for higher education. That is to say, these "guideline" documents espouse equity and inclusion, partnership, supportive relationships (belonging), and transformative learning experiences (becoming). My personal values were well aligned, and I aspired to embed these values within my professional practice.

Practising within this new model required midwives to work in significantly different ways from that to which they were accustomed. Consequently, developers 
including myself, had collaboratively designed and offered new educational opportunities for midwives and others who were most closely and frequently involved in ANC, within the NHS Trust. One education offering was a continuing professional development module within which I designed and led one of four workshops. The module philosophy firmly recognised "learning by doing" (Cottrell, 2015), where role plays, practice, simulations and role modelling were incorporated. We recognised "becoming" a successful ANC group facilitator would only occur once participants' learned skills, knowledge and attitudes were transferred into the practice environment.

Prior to my recent foray into "autobiographical" reflective pedagogical AR which will be elaborated on here, my only experience of AR was in the context of participatory action research (Wadsworth, 2001) in the "international community development" field. The approach was used to engage and empower communities to prioritise and work on identified determinants of health and well-being.

\section{Getting Started with Action Research: Initial Observations and Reflections}

The starting point of AR has been discussed by Altrichter, Feldman, Posch, and Somekh (2008), with Elliott (1991, pp. 73-75) who has offered the term "reconnaissance" to describe the AR activities of (a) "describing the facts of the situation", and (b) "explaining" these facts. As outlined, the context of my teaching was within a continuing professional development module for midwives-with varying levels of academic learning experience — offered as part of broader service innovation.

Several observations initially contributed to a curiosity about this topic area and then, following some informal "information gathering" (discussion with colleagues) and reflection, my AR focus was decided. While I noted the wealth of cultural and ethnic diversity apparent within the "student body" (midwife colleagues) in the East London context, it also appeared that this diversity was not proportionately reflected within leadership and/or senior management positions in the health services. A search of published and grey literature revealed that there was, indeed, a general phenomenon of differential opportunity across the NHS (Kline, 2015), and what appeared to be evidence of discrimination in this specific professional context (RCM, 2016a, 2016b).

Upon observation of the NHS Trust's "organisational environment", another realisation became apparent - the need to empower midwives (Ryan \& Tilbury, 2013) to empower women. Findings from research conducted within the context had indicated that midwives often felt fearful (RCM, 2015) and disempowered (RoccaIhenacho, 2016) due to the organisational culture and environment, leading to a general unwillingness to change or try something new (McKellar, Pincombe, \& Henderson, 2009). 
Another observation was made regarding my other colleagues in this contextmidwifery academics and educators across several university campuses in Londonwhere there seemed rarely to be a person of a minority heritage. While not having access to location-specific data, I nevertheless became more informed through referring to relevant research (Alexander \& Arday, 2015). With regard to particular learners, I heard "deficit discourses" during discussions, which caused me some discomfort. Within the module in which I taught, while it was clear that some midwives had well-developed skills (an existing level of competency) in group facilitation (the main learning outcome of the module), several learners voiced fears about not being experienced or capable in the "academic sphere". I wondered about the impact of these issues on women being cared for within the services, on the everyday lives and working lives of midwives in general and, particularly, on the everyday lives and working lives of midwives of ethnic-minority heritage. More precisely, I wondered what this might mean for me, as a "teacher", in this learning environment, and the types of challenges I might face. How would I ensure quality, equitable and relevant learning (and teaching) opportunities in my "classroom"? Who and what was available to guide me in this context? While having spent approximately six years immersed (Wood \& Atkins, 2006) in several countries and cultures of Asia, and having completed a learning experience in "culture, subculture and communication"; realisation of deficits on my part, with regard to other population/cultural groups prevalent within my current circle, was an additional influencing factor for my decision to select the AR approach for exploration of the issues identified.

My ongoing observations seemed mutually reinforcing, rather than challenging my initial analysis. A chance to conduct AR in cultural proficiency, as part of a formal qualification in learning and teaching, and to further my understanding, seemed like a valuable opportunity. The idea of doing or trying something "concrete" (Kemmis \& McTaggart, 1988) in an attempt to improve the situation was appealing; developing an "intervention", testing its effectiveness and utility, all within a context of reflection and referral to multiple sources of "data", seemed valuable in itself. Evaluating various outcomes through AR with reference to multiple forms of "knowledge" (Odora Hoppers, 2002), and with the understanding that the process was ongoing and the learning intervention could be and/or would be revised, was an added bonus.

\section{Action Research Framework and Method: What is AR and Why Use It in This Context?}

The main justification for the selection of AR in the context described was that such an approach encourages the cultivation of "an inquiry stance" (Chapman, Lewis, Osborne, \& Gray, 2013, p. 130). I felt this approach to research provided significant advantages and was particularly relevant, not only to me as a teacher, but because at the core of cultural proficiency is reflexivity. Additionally, I had the sense that a reflective approach would be less "threatening" in terms of the expectation that 
participants engaged in an AR process would "step outside their comfort zones", and in the case of some of my learners, that they could "contribute" and participate (i.e. in reflection) without having to respond overtly (i.e. in the presence of others). The overall aim, therefore, was to create not only "a community of practice" for educators (Wenger, 2012), but a "safe learning community" for all.

Upon consideration of various options proposed in the published literature, the AR model that seemed to provide the best framework for the research processes upon which I was embarking was O'Leary's "cycles of research" (O'Leary, 2004, p. 140) (see the adaptation of this model at Fig. 17.1). In my application of this model, "observation" included research/data collection from various sources.

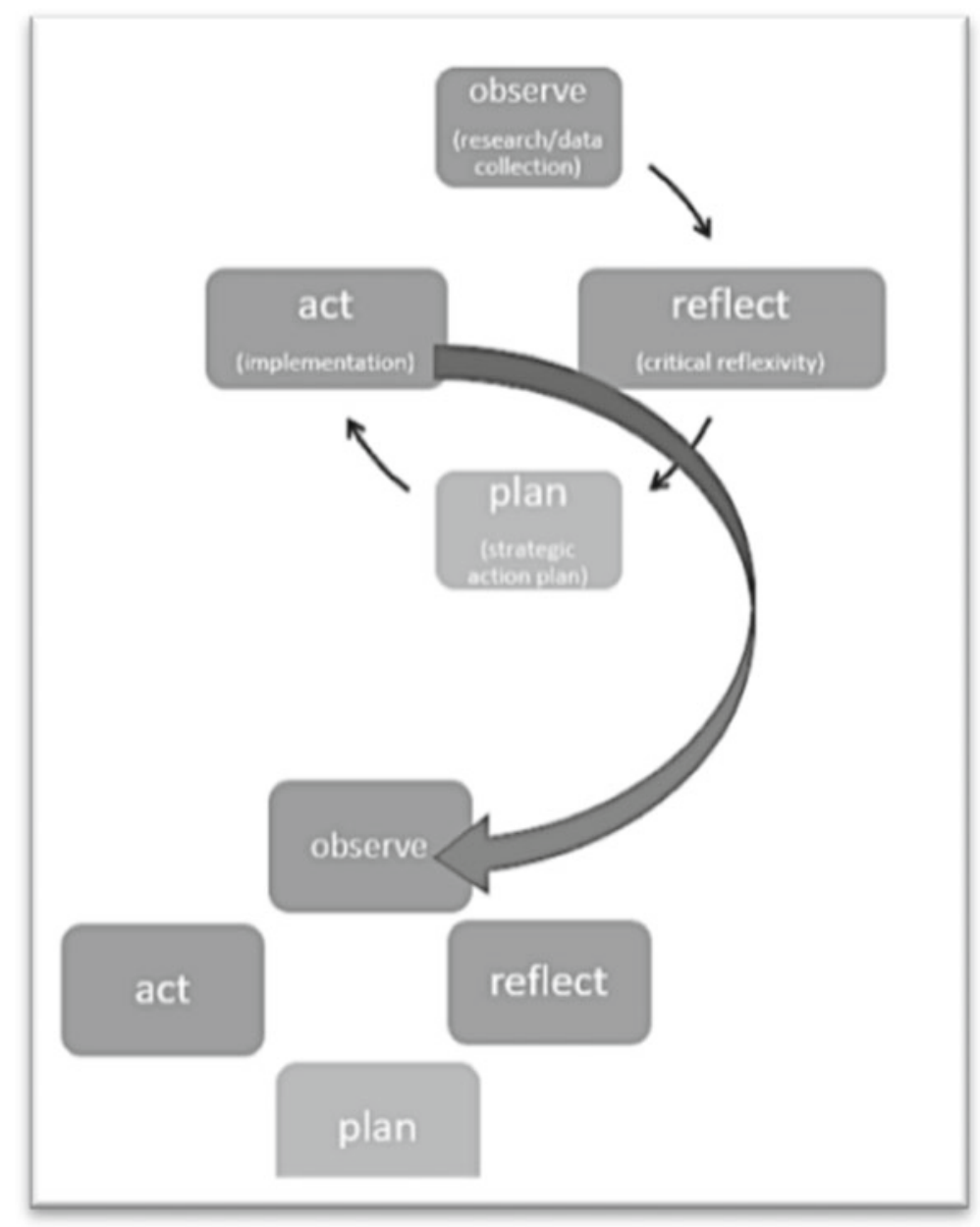

Fig. 17.1 Adapted from O'Leary's Cycles of Action Research 


\section{Developing the Initial "Active Inquiry" Proposal: Engaging in Planning for Action Research}

Initially, I gained a sense that there might be a lack of cultural competence learning within midwifery education in the UK. This was confirmed by discussion with several senior academic colleagues, a literature search of relevant databases using appropriate key terms (cultural competence, midwifery, education and variants), and a scoping exercise where I consulted experienced and knowledgeable academic/research colleagues via an international midwifery research email list.

At the proposal writing stage, I identified the topic area for the AR, provided a basic introductory background and rationale, outlined what I hoped to learn, sketched a brief theoretical framework supporting my practice and proposed intervention, and described the planned methods, while also reflecting on ethical (British Educational Research Association, 2011) and practical considerations. ${ }^{1}$ The proposal was developed from a combination of various "voices" (based on Brookfield's four critical lenses; see Brookfield, 1995) where the ongoing desire to work towards social change (Griffiths, 1998) in and outside the classroom, seemed to make the chosen issue of focus, "cultural competence in midwifery", amenable to AR. Additionally, my teaching practice environment seemed an ideal opportunity to draw upon the "assets" present in the classroom to facilitate learning for all. Additionally, my teaching practice environment seemed an ideal opportunity to draw upon the 'assets' present in the classroom to facilitate learning for all. An asset-based approach is in contrast to deficit thinking frequently observed (e.g. see Bouattia, 2015).

As another step in the cycle, more information gathering to inform planning took place (i.e. the uses of AR in the discipline of midwifery were investigated). The large majority of recent publications utilising AR methods focused on change in midwifery practice, not midwifery education (see, e.g., Nyman, Berg, Downe, \& Bondas, 2015; McKellar, Pincombe, \& Henderson, 2002; McKellar, Pincombe, \& Henderson, 2008; McKellar et al., 2009; Moore, Crozier, \& Kite, 2012). However, some publications had focused on undergraduate (pre-registration) midwifery (and nursing) curricula (Fraser, 1996, 1999, 2000a, 2000b; Smith et al., 2000; Wilkins, Leamon, Rawnson, \& Brown, 2008). Some focused on improving research skills (Crozier, Moore, \& Kite, 2012; Nikbakht, Parsa, \& Barimnejad, 2005); others, on reflective practices of [nurse] educators (Smith, Gentleman, Loads, \& Pullin, 2014); and others, on midwives' supervision support (Deery, 2005). Possibly of most relevance to my fledgling ideas, this search located two studies that evaluated cultural competence education within undergraduate nursing programmes (Reid, 2010, Bond); one investigating experiences of cultural competence educators (Wepa, 2003); one investigating the use of an online tool promoting cultural humility (Sreenivas et al., 2015); and one evaluating the extent to which a particular health concept had been integrated into health professionals' curricula (Smith et al., 2000).

\footnotetext{
${ }^{1}$ Note: an ethics review process was not engaged in, as the proposed research did not progress to the implementation phase.
} 
Table 17.1 A representation of the Action Research process (Kildea, Barclay \& Brodie, 2006)

\begin{tabular}{l|l}
\hline Aim & Reducing isolation from educational resources \\
\hline Theory & Computer mediated communication \\
\hline Approach & Participatory action research \\
\hline Tool & Information technology and the navigator \\
\hline Result & Maternity care in the bush website \\
\hline Evaluation & Reach, agency affiliation, barriers and facilitators \\
\hline
\end{tabular}

Overall goal: Strengthening remote area maternity services

AR processes were applied to develop and evaluate a learning tool (see Table 17.1), and this approach resonated with some of the initial ideas for my chosen project.

\section{Taking Action}

Following the above steps, the overall aim of this research project became: to facilitate "cultural exchange" and learning within midwifery [education]. A "partnership approach" to learning (HEA, 2009; Healey, Flint, \& Harrington, 2014; Smith et al., 2000) means teachers learn from students, students learn from each other, students learn from the teaching and modelling of culturally competent teachers, and professional colleagues share with and learn from each other (Wenger, 2012); and we all learn by applying our learning in practice. Therefore, it is necessary to understand the learning needs of both midwifery students and faculty in this domain, to achieve the anticipated improvements in cultural proficiency in midwifery care. In my context, there were opportunities to draw on the diversity within the student body to enhance our "being" competent midwives and midwifery educators, since midwifery education is recognised as "transformation to competent practice" - that is, learning, knowing, becoming and being (HEA, 2009).

\section{Developing the Theoretical Framework: A Logic Model and Rationale for Increasing Intentional Learning Opportunities in Cultural Competence for Midwives}

Through previous work, I was familiar with "cultural safety" in the discipline of nursing (Ramsden, 2002); however, very little published literature could be located about this topic within midwifery. Relevant work was found in allied health and medicine, so I decided to widen the search to include evidence from other health care disciplines. This literature review occurred iteratively in several "waves", according to the need to inform the AR, as identified, during the reflective cycles. Initially, the 


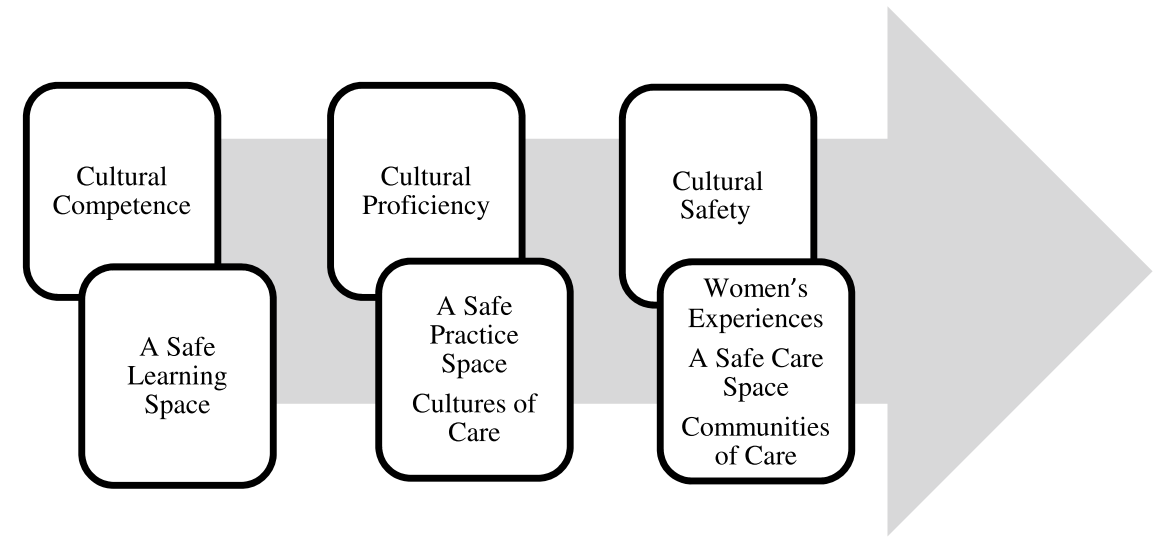

Fig. 17.2 A logic model of action research in cultural competence, proficiency and safety in maternity care and education

search was focused on the literature in the chosen topic area: cultural safety, proficiency and competency, within midwifery. Next, as previously explained, existing work on AR within the discipline of midwifery was sought. To articulate the underpinning rationale and facilitate evidence synthesis, it became necessary to propose a working logic model (see Fig. 17.2) to describe the planned AR and to illustrate connections between the key concepts under consideration. This also provided further justification for the chosen research aim, objectives and methods.

Based on evidence gathered using the "four critical lenses" (Brookfield, 1995), in this case the views and experiences of service users, other literature, my own observations and colleagues' experiences, I asserted in the AR proposal that the aspiration was cultural safety (Ramsden, 2002) within maternity care and education. I proposed this would only be achieved within culturally proficient practice cultures and communities; and by acknowledging midwifery as an Art and a Science but extending the "head and hand" to add "heart" (the interpersonal component). These views, I argued, would only be developed through the achievement of cultural competence at both individual and organisational levels. Furthermore, it has been asserted that to achieve competency in intercultural contexts, appropriate learning experiences must be provided (Nairn, Hardy, Harling, Parumal, \& Narayanasamy, 2012), and that self-reflection is a key component of learning processes (Williamson \& Harrison, 2010). Following the process of critical reflection, the question was asked: why do we need cultural safety and proficiency in maternity care systems anyway? In the broadest sense, it seems unequivocal that cultural aspects influence personal views of health and illness (Tseng \& Streltzer, 2008). Our cultural embeddedness becomes a frame of reference through which we experience care, and care experiences are informed by our subconscious beliefs about what constitutes appropriate behaviour and "treatment" during significant life events such as births, deaths and illnesses (Tseng \& Streltzer, 2008). Wikberg et al. (2014) argued that culturally competent health services are a core component of "caring". They asserted that 
caring is universally expected of health services. Cultural beliefs and practices significantly influence health care-seeking behaviour, and this can affect subsequent health outcomes (including life and death; e.g. choices around treatment options). Research has found there are poorer health outcomes for women from minority ethnic groups within the UK, even after controlling for potential confounders (Hayes et al., 2011). Broadly, inequalities in health outcomes and care are well documented (Betancourt et al., 2003; Smedley, Stith, \& Nelson, 2003).

Women's experiences of birthing and their maternity care have a strong influence on their subsequent adjustment to parenthood (e.g. dealing with a traumatic experience), and even longer-term maternal and infant health and well-being (e.g. attachment and parenting) (Barlow \& Parsons, 2005). More specifically, "culturally sensitive care" has been shown to influence birth outcomes (Downe, Finlayson, Walsh, \& Lavender, 2009). Women from culturally and ethnically diverse groups have been found less likely to report positive experiences of maternity care (Ali \& Burchett, 2004; Small, Liamputtong Rice, Yelland, \& Lumley, 1999).

The NHS is recognised as an employer with high levels of ethnic diversity in its staff. However, this diversity has not been reflected in higher position levels, and disciplinary action has been reported as more common among staff from minority groups (Kline, 2014; RCM, 2016a). In terms of regulatory standards, policies and guidelines for practice and education in the UK context, the Nursing and Midwifery Council (NMC) admonishes cultural sensitivity in health care (NMC, 2015), as does the RCM. The World Health Organisation (WHO) urges that education be culturally relevant and incorporate diversity (WHO, 2013). There is clearly a need for midwives competent to provide quality care in this respect; however, a lack of cultural competence within maternity care has been found (Noble, Engelhardt, Newsome-Wicks, \& Woloski-Wruble, 2009).

Betancourt et al. (2003, pp. 297-299) outlined three levels or types of interventions for improving cultural competence: (a) "clinical cultural competency interventions"- that is, at the individual level and manifest "at the bedside"; (b) "structural" interventions; and, (c) "organisational" interventions. Following Betancourt et al. (2003, p. 298), I suggested that interventions addressing cultural competence at the organisational level —in this case, hospital and health services environments-were, due to the highly hierarchical nature of such organisations, synonymous with "structural cultural competency interventions". I argued the aim was to promote "cultures of care" or "a safe practice space" for midwives and other health care workers, rather than just safe care for "patients/women" (McKee, West, Flin, Grant, \& Johnston, 2010). Napier et al. (2014, pp. 1608-1609) asserted the need for "reshaped" clinical cultures in health care institutions, rather than historical "prestige hierarchies".

It has been argued that "managerialism" within the NHS can militate against culturally proficient care, due to time pressures and efficiency measures placed on staff (Hollinsworth, 2013, p. 1053). Kleinman and Benson (2006) asserted the need for "culturally informed care", as opposed to health systems and services that have been defined as "monocultural" and Anglo-dominated (Cioffi, 2004). The need for health care organisations to build partnerships with communities has been asserted (Latif, 2010), as well as the need for connections to be made between public sector 
organisations and civil society (UNESCO, 2001). In order for these aspirations to be realised, in attempting to build political will for faculty engagement in the AR process, I argued an attitude of "cultural humility" was needed (Sreenivas et al., 2015; Wikberg \& Eriksson, 2008).

Following Betancourt et al. (2003), I argued that "organisational cultural competency interventions" were also required to enable safe learning spaces for diverse learners (Hockings, 2010; Husbands \& Pearce, 2012; Mountford-Zimdars et al., 2015; Pitkajarvi, Eriksson, \& Pitkala, 2013; Sobel \& Taylor, 2011). This would involve "reorienting pedagogies" and "decolonising education" in the context of my project (Ryan \& Tilbury, 2013). Tileston and Darling (cited by Bostrom, 2011, p. 1) noted "achievement data from recent ... tests document that culture has a greater impact on the gaps in achievement than does poverty". Cultural competence of teaching staff cannot be assumed, and in order to achieve this in the classroom, I assert that intentional learning opportunities are needed for teaching practitioners (Kripalani, Bussey-Jones, Katz, \& Genao, 2006; Miller, 2001). Frenk, Chen, Bhutta, Cohen, and Al (2010, p. 1923) have asserted the need for the "redesign of health [professionals'] education" including reciprocity and partnership, recognising "opportunities for mutual learning". In terms of the teaching body the need to "promote cultural diversity ... at all level[s]" has been emphasised (Kripalani et al., 2006, p. 1118).

Following reflection on this evidence, I wondered where to begin with learning and teaching in cultural competence. Aligned with, and going back to, the principle of transformative learning, becoming culturally proficient and understanding diverse cultures requires learners to engage in critical self-reflection about, and on, their own culture(s) and subcultures (Bostrom, 2011; Hollinsworth, 2013). I would go on to argue that before this process could begin, a fostering of "cultural desire" was needed (Wikberg \& Eriksson, 2008), as well as a willingness to change one's attitudes and behaviour (Michie, Van Stralen, \& West, 2011).

Learning experiences in the area of cultural competence need to go beyond "shopping list" approaches with "static notions of culture" (Jenks, 2011), to avoid "cultural racism" and "deterministic interpretations" (Hollinsworth, 2013). An "openmindedness" (Jenks, 2011) needs to be fostered, and a recognition that "diverse cultural identities are negotiated", and there must be a willingness to "learn from" others as individuals, rather than think we know "about" them (Hollinsworth, 2013).

My search then turned to existing cultural competence curricula, modules and tools being used within midwifery, and ideally applying a transformative learning approach (Mezirow, 1997) that is not just about knowledge acquisition, but developing and changing thinking capability to bring about new ways of being in the world. Finding that more work in this field had been done within curricula for health professionals other than midwives-for example, social work (Lenette, 2014), allied health (Lubinski \& Matteliano, 2008; Ronnau, 1994), nursing (Reid, 2010) and medicine-I then considered possibilities for utilising a relatively new approach: that of "interprofessional learning" (Barnsteiner, Disch, Hall, Mayer, \& Moore, 2007; Cullen, Fraser, \& Symonds, 2003; Furber et al., 2004; Murray-Davis, Marshall, \& Gordon, 2011). 
Service-user involvement, which is being utilised more frequently in the development of programmes and curricula for health care professionals (Chambers \& Hickey, undated; Towle et al., 2010), would arguably be another useful input in this context.

Realising the complexity of developing a useful learning intervention in this area, I began to search course work resources and academic literature for more information to aid in decision-making about selecting the most effective pedagogical methods for my two "learners" and context, and to choose the most appropriate content (Beach et al., 2005).

\section{Developing the Intervention Tools: Methods Used}

Having opportunistically discussed my interest in the area of improving cultural competence in midwifery with senior midwifery colleagues-three female academics-I envisaged their support for introducing two first-stage individual-level interventions. These would be formatted as simple questionnaires, prompting selfreflection on attitudes, experiences and beliefs; and developed, with the appropriate permissions, from tools and methods used in other contexts, as found in the literature (C2ME, 2015; MSH, 2008; Papadopoulos, Tilki, \& Ayling, 2008; Sutton, 2000).

The choice of this approach was informed by Kolb (1984, see pp. 20-38). Rather than gathering information to assess cultural competence per se, as done in some research studies (e.g. studies listed in Carey, 2011), a key objective would be to initiate a dialogue that included the experiential learnings and reflections of participants "grounded in [their] experience[s]" (Kolb, 1984). This would enhance the process of knowledge creation and widen the interpretation to include experiential knowledge of participants, as well as my own knowledge gained from engaging in the AR process. Similarly, Mulligan (1993, pp. 54-57), explained the activation of "internal processes" during experiential learning, such as "remembering", "sensing" and "imagining", and it was expected that these would be initiated while engaging with the questionnaires. While Elliott (1991, p. 49) stated "the fundamental aim of action research is to improve practice rather than to produce knowledge", I argued that in my context it was the production of these alternative knowledges that would lead to improved practice through engagement in the AR cycle. At the same time, I recognised my "researcher bias", and referred to the "typological contrasts" made between "research as evidence and research as pedagogy" (Campbell \& Groundwater-Smith, 2007, pp. 69-72). Another key objective was to move midwife participants from what was arguably their dominant domain of "technical rationality" (i.e. the NHS and academia), into a space of "reflection-in-action" (Schön, 1991, pp. 21-69). Undertaking this initial AR process, it was envisaged, would also inform development of the later stage(s) of the AR (see "cycles within cycles", Dick, 2000) such as the utilisation of various learning "tools" aiming to improve cultural competence.

Subsequently, following another database search, and using key words related to cultural competence instruments or tools, I located "organisational cultural competency" assessment tools and experiences (e.g. Cherner, Olavarria, Young, Aubry, \& 
Marchant, 2014; LaVeist, Relosa, \& Sawaya, 2008; Lavizzo-Mourey \& Mackenzie, 1996), necessitating consideration of using this approach either concurrently or sequentially, in combination with those originally proposed for individual-level use. Utilisation of such an organisational-level tool would acknowledge the broader context of learning; that is, the "real-world environment" (Kolb, 1984, pp. 3436) within which my learners work and learn (i.e. in the NHS). A further targeted search uncovered a considerable body of work relevant to the pedagogical aspects of cultural competence education initiatives. It was clear that any new intervention to be developed would benefit from incorporating this evidence (Campinha-Bacote, 2008). Existing teaching methods reported on included, for example, the development and use of e-learning (C2ME; Hawthorne, Prout, Kinnersley, \& Houston, 2009) and simulation methods (Rutledge, Barham, Wiles, \& Benjamin, 2008), and the publication of learning experiences and learning support documents (Dogra, Reitmanova, \& Carter-Pokras, 2009; Kleiman, Frederickson, \& Lundy, 2004; Miller \& Green, 2007; Reid, 2010; Thackrah \& Thompson, 2013; Torry, 2005).

\section{The Intervention: Reflecting on Our Experiences, Beliefs and Attitudes Around Intercultural Midwifery; and Two Self-assessment Tools for Learners and Teachers}

From my synthesis of the literature on cultural competence education, it became apparent that there was little consensus regarding the most effective approaches and methods (e.g. Abrams \& Moio, 2009; Campinha-Bacote, 2008; Hollinsworth, 2013; Wells, 2000; Wood \& Atkins, 2006). Various limitations with regard to some expected outcomes (Brach \& Fraserirector, 2000) had been noted as well; for example, an impact on reducing health inequalities had not been determined. Following reflection on findings from the extensive review of evidence and discussion in the literature (referred to above), as well as discussions with colleagues, I decided my proposed interventions would take the form of a two-strand and staged approach. The first stage and strand would be to invite students (registered midwives undertaking the Continuing Professional Development module) to complete a short questionnaire in response to the question: "How can I utilise and optimise cultural proficiency/competency skills in the context of group ANC?" This question was considered directly relevant to the learning objectives of the module in which they were enrolled, and also aligned with the overall research programme we were implementing, aimed at improving equity in birthing outcomes among a "superdiverse" population.

The proposed second strand would be an invitation to academic colleagues (midwifery educators, lecturers and preceptors) to complete a short questionnaire in response to the question: "How can we utilise and optimise cultural proficiency/competency skills in the context of midwifery education?" Such a question is relevant to the overall aims and aspirations of the health services and aligned with 
professional responsibilities — of providing "culturally sensitive" midwifery care and requiring learning opportunities for midwives to be incorporated into existing curricula.

While these are two separate "interventions"- one inside the classroom with the student body, the other with faculty colleagues - the focus was the interface between the two groups. As expressed in my aim (outlined above), it was hoped that positive "shifts" would be evident in participant responses, both within "the classroom" (or learning context; e.g. online learning environment) - that is, between faculty and learners - and also, ultimately, a "social transformation" (Criticos, 1993) in the health care setting, where learners would "do", and ultimately "become". Personal and professional values apparent in the concepts and proposed inquiry were centred around "expression/voice/dialogue", "fairness/equity", and "reciprocity". While the interventions themselves were expected to generate "hard data", it was the reflections on the process and responses of those involved, including "self-critical" reflection (Bassey, 1995, p. 3), that were the key outcomes of interest, as these responses would provide evidence of shifting attitudes, and assist in determining the next step in the AR cycle.

\section{Recording and Evaluating the Intervention: Planned Methods}

Crucial to enhancing the validity of this AR process, and utilising writing as a reflective tool (Bolton, 2010); a reflective journal was utilised (McNiff, 2002). This enabled subsequent changes in the initial "action plan" to be logical and allowed for documentation of any justification for changes throughout the iterative process.

My plan was initially to circulate draft copies of the two tools for suggestions from colleagues, engaging them in the AR process not only as "participants" (Koshy, 2005, p. 21) but as "members of a profession" (Altrichter et al., 2008, pp. 268-278). Another rationale for including this step was the principle that colleagues have knowledge and experience that is worth exploring (Baumfield, Hall, \& Wall, 2008, pp. 62-77). Assuming two suitable tools could be produced, these would then be "pretested" on one class group, meaning a process of analysis and reflection would occur to assess validity of responses.

During and following introduction of the intervention, methods of evaluation would include assessing intended, and any unintended, outcomes through feedback from learners; views and opinions of faculty and managers; and my own observations and reflections on the processes and outcomes, using the "Johns" model for structured reflection" (cited in Moon, 1999, p. 71), which has been described as "a practical stance" applicable for use in "the professions". Negative reactions from some would be expected, based on the work of others around "white fragility" (DiAngelo, 2018). Some particularly useful questions to guide this process were also found (Dick, 2002). My own observations and evaluations about the process would include making sense 
of informal responses from colleagues and students about the introduction of the interventions, as well as comments made during the "debriefing" following participation. Documenting experiences/reflections of my teacher colleagues at a follow-up session might be useful (Wepa, 2003), as new situations/experiences might trigger deeper reflection. This "feedback" would be used to reflect on, during and after, and to assess "organisational readiness" for proceeding to a next-stage intervention and/or refining or adjusting the original one.

\section{Actual and Expected Outcomes: Reflecting on What Happened and Why}

While the above AR process is presented as sequential and according to the steps outlined in AR methods, in actuality, the processes of reflection and information gathering were intertwined within each step. While being engaged in the steps of observation, reflection, planning and action, I did not manage to progress fully through the proposed AR cycle. Following the literature synthesis, and reflection on the proposed work brief presented to a different group of colleagues, Macintyre's model (cited by Koshy, 2005, pp. 7-8) seemed to fit where I progressed to, as he describes forming a tentative action plan and then going about refining it.

The opportunity to undertake the project in a reflective and informed way was an important learning experience. As with most innovations, I expected varying degrees of acceptance and resistance, and expected that time would be needed to develop engagement with a "critical mass" or, alternatively, that this might never be achieved. Following presentation of the preliminary evidence and rationale, I decided more consideration of "political" contexts was required, as there seemed to be anxieties and tensions among many of my colleagues around "culture" and "political correctness". Recognising some people may find their values and assumptions (as well as power) being challenged, I considered that conversations with more colleagues might be needed to encourage "gentle" movement from existing comfort zones. If the opportunity to replicate this project in another setting is ever presented, I expect to encounter different beliefs about the value of the proposed initiatives or interventions. I anticipate that adjustments will need to be made to the questionnaire, based on the responses from a pilot. The responses from senior managers and leaders, I surmise, will be indicative of several factors such as their commitment to issues of equality and fairness (in practice), their own experiences and outcomes of reflective processes, and their organisational resource constraints and competing priorities; as well as the fact that the conditions and/or facilitators for reflection (Moon, 1999, p. 176) will not always be present, or present in adequate amounts.

My aspirations for this work include improved critical reflection (Larrivee, 2000) for more "culturally responsive teaching" (Norton \& Bentley, 2006). Giving "voice" (Griffiths, 1998, pp. 117-128) to the various views and classroom experiences of culturally and ethnically diverse learners will, I envisage, necessitate consideration 
of ethical obligations and values (Bolton, 2010) at personal and organisational levels, and prompt action on inequities; or if that action does not take place then, at the least, require justification for non-action.

It was my expectation that through engaging in this AR project, I would be empowered to plan further "interventions" in my classroom, better incorporating diversity and inclusive materials, techniques, and methods. This outcome would enrich my "authentic presence", enabling me to more effectively apply my values in practice. It would be expected that these would all enhance the effectiveness of teaching and learning for my students.

\section{Conclusion}

In my view, the significance of this inquiry, an AR process with a proposed intervention, was three-fold. Firstly, regarding my own teaching practice, the initiation of this work around cultural competence in (midwifery) learning environments ensured a continuing process of self-reflection on my own skills deficits and proficiencies which would, it was envisaged, lead to ongoing learning and positive change. I would value exploration in use and application of Ghaye's (2011) "strengths-based reflective practice". Secondly, the process of engaging in AR in learning and teaching has helped me make a connection between the integration of my research practice and role, and my teacher-as-researcher role, thereby expanding my thinking around "quality research". Thirdly, becoming more aware of and intentional about my reflective processes has been enlightening and encouraging, and I feel empowered to utilise Brookfield's (1995) lenses, in a practical way, to provide "holistic" analyses.

Putting the above into practice within the various learning environments that $\mathrm{I}$ traverse will, no doubt, be sometimes challenging, but I hope my confidence will develop through positive reinforcement. In respect of the broader learning environments within which I taught, and continue to teach, I believe that including questions around cultural competence will open spaces for dialogue and, through that process, positive change in respect to cultural competence can be made at both organisational and individual levels. In the context of my research practice, partnerships with various colleagues and groups enabled access to a broader network. This network can make further contributions to the development of initial ideas; and some resources accessed to test, implement and evaluate the tools discussed here can possibly then be applied at scale. Paying attention to the socio-political contexts of midwifery education and research will, it is hoped, further enhance outcomes for the health services as a whole, for practising midwives, and for women and families.

Acknowledgements I would like to acknowledge and thank the many midwives in London with whom I worked and associated, and who shared with me their experiences, and my journey. I learned and came to understand so much from being with you, even though for only a brief time. My thanks and acknowledgement to Dr. Warren Kidd, who guided me in the AR process and provided some 
suggestions on a very early draft of this manuscript. You really set me on this whole pedagogical and reflective practice trajectory, a very valuable learning experience indeed. Thanks also to Ms. Olivene Yasso who generously provided comments and suggestions on the oral presentation of this work-our yarning/sharing is always enlightening.

\section{References}

Abrams, L. S., \& Moio, J. A. (2009). Critical race theory and the cultural competence dilemma in social work education. Journal of Social Work Education, 45, 245-261.

Alexander, C., \& Arday, J. (2015). Aiming higher: Race, inequality and diversity in the academy. London: Runnymede.

Ali, N., \& Burchett, H. (2004). Muslim women's experiences of maternity services. London: Maternity Alliance.

Altrichter, H., Feldman, A., Posch, P., \& Somekh, B. (2008). Teachers investigate their work: An introduction to action research across the professions. London: Routledge.

Barlow, J., \& Parsons, J. (2005). Group-based parent-training programs for improving emotional and behavioural adjustment in 0-3 year old children: A systematic review. Retrieved from https:// www.campbellcollaboration.org/lib/project/6/. Campbell Systematic Reviews.

Barnsteiner, J. H., Disch, J. M., Hall, L., Mayer, D., \& Moore, S. M. (2007). Promoting interprofessional education. Nursing Outlook, 55, 144-150.

Bassey, M. (1995). Creating education through research: A global perspective of educational research for the 21st century. Newark: Kirklington Moor Press \& British Educational Research Association.

Baumfield, V., Hall, E., \& Wall, K. (2008). Action research in the classroom. London: SAGE.

Beach, M. C., Price, E. G., Gary, T. L., Robinson, K. A., Gozu, A., Palacio, A., et al. (2005). Cultural competence: A systematic review of health care provider educational interventions. Medical Care, 43, 356-373.

BERA. (2011). BERA ethical guidelines for educational research. British Educational Research Association.

Betancourt, J. R., Green, A. R., Carrillo, J. E., \& Ananeh-Firempong, O., II. (2003). Defining cultural competence: A practical framework for addressing racial/ethnic disparities in health and health care. Public Health Reports, 118, 293-302.

Bolton, G. (2010). Reflective practice: Writing and professional development. London: SAGE.

Bond, P. (n.d.). Developing, implementing, and evaluating cultural competency and equality in nurse training: what are we learning? Results from an action research project to mainstream cultural competencies and equality training in the nurse curriculum. Retrieved from https://www2.wlv. ac.uk.

Bostrom, C. (2011). Becoming culturally proficient in the classroom. International writers block, edublogs [online]. Retrieved from: https://internationalwritersblock.edublogs.org/files/2011/07/ 8-Edublog-Becoming-Culturally-Proficient-in-the-Classroom-15dono8.pdf.

Bouattia, M. (2015). Beyond the gap: Dismantling institutional racism, decolonising education. In C. Alexander \& J. Arday (Eds.), Aiming higher: Race, inequality and diversity in the academy. London: Runnymede.

Brach, C., \& Fraserirector, I. (2000). Can cultural competency reduce racial and ethnic health disparities? A review and conceptual model. Medical Care Research and Review, 57, 181-217.

Brookfield, S. D. (1995). Becoming a critically reflective teacher. San Francisco: Jossey-Bass.

C2ME. (n.d.). Assessment tool. Retrieved from https://www.amc.nl/web/Research/Overview/ Major-projects-and-collaborations/Culturally-Competent-in-Medical-Education/CulturallyCompetent-in-Medical-Education/Project-C2ME.htm. 
C2ME. (n.d.). Culturally appropriate teaching for Medical Educators [E-Learning Package]

[Online]. Culturally Competent in Medical Education. Accessed April 11, 2016.

C2ME. (2015). Summary of the symposium culturally competent in medical education. Amsterdam: University of Amsterdam.

Campbell, A., \& Groundwater-Smith, S. (2007). An ethical approach to practitioner research. London: Routledge.

Campinha-Bacote, J. (2008). Cultural desire: "caught" or "taught"? Contemporary Nurse, 28, 141148.

Carey, R. E. (2011). Cultural competence assessment of baccalaureate nursing students: An integrative review of the literature. International Journal of Humanities and Social Science, 1, 258-266.

Chambers, M., \& Hickey, G. (n.d.). Service user involvement in the design and delivery of education and training programs leading to registration with the Health Professions Council. Kingston University and St George's, University of London.

Chapman, H., Lewis, P., Osborne, Y., \& Gray, G. (2013). An action research approach for the professional development of Vietnamese nurse educators. Nurse Education Today, 33, 129-132.

Cherner, R., Olavarria, M., Young, M., Aubry, T., \& Marchant, C. (2014). Evaluation of the organizational cultural competence of a community health center: A multimethod approach. Health Promotion Practice, 15, 675-684.

Cioffi, J. (2004). Caring for women from culturally diverse backgrounds: Midwives experiences. Journal of Midwifery \& Women's Health, 49, 1-7.

Cottrell, S. (2015). Learning and teaching strategy 2015-2020. Presentation. London: UEL.

Criticos, C. (1993). Experiential learning and social transformation for a post-apartheid learning future. In D. Boud, R. Cohen, \& D. Walker (Eds.), Using experience for learning. Buckingham: The Society for Research into Higher Education \& Open University Press.

Crozier, K., Moore, J., \& Kite, K. (2012). Innovations and action research to develop research skills for nursing and midwifery practice: The Innovations in Nursing and Midwifery Practice Project study. Journal of Clinical Nursing, 21, 1716-1725.

Cullen, L., Fraser, D., \& Symonds, I. (2003). Strategies for interprofessional education: The interprofessional team objective structured clinical examination for midwifery and medical students. Nurse Education Today, 23, 427-433.

Deery, R. (2005). An action research study exploring midwives' support needs and the effect of group clinical supervision. Midwifery, 21, 161-176.

DiAngelo, R. (2018). White fragility: Why it's so hard for white people to talk about racism. London: Penguin Books.

Dick, B. (1998). Reflective mechanisms. Retrieved from https://www.uq.net.au/action_research/arp/ reflmech.html.

Dick, B. (2000). Resource papers in action research: Cycles within cycles. Retrieved from https:// www.aral.com.au/resources/cycles.html.

Dick, B. (2002). Questions for critical reflection. Retrieved from https://www.uq.net.au/action_res earch/arp/reflques.html.

Dogra, N., Reitmanova, S., \& Carter-Pokras, O. (2009). Twelve tips for teaching diversity and embedding it in the medical curriculum. Medical Teaching, 31, 990-993.

Downe, S., Finlayson, K., Walsh, D., \& Lavender, T. (2009). Weighing up and balancing out: A meta-synthesis of barriers to antenatal care for marginalised women in high-income countries. BJOG, 116, 518-529.

Elliott, J. (1991). Action research for educational change. Buckingham: Open University Press.

Fraser, D. M. (1996). Pre-registration midwifery programs: A case study evaluation of the nonmidwifery placements. Midwifery, 12, 16-22.

Fraser, D. M. (1999). Delphi technique: One cycle of an action research project to improve the pre-registration midwifery curriculum. Nurse Education Today, 19, 495-501.

Fraser, D. M. (2000a). Action research to improve the pre-registration midwifery curriculum. Part 2: Case study evaluation in seven sites in England. Midwifery, 16, 277-286. 
Fraser, D. M. (2000b). Action research to improve the pre-registration midwifery curriculum. Part 3: Can fitness for practice be guaranteed? The challenges of designing and implementing an effective assessment in practice scheme. Midwifery, 16, 287-294.

Frenk, J., Chen, L., Bhutta, Z. A., Cohen, J., \& Al, E. (2010). Health professionals for a new century: Transforming education to strengthen health systems in an interdependent world. The Lancet, $376,1923-1958$.

Furber, C., Hickie, J., Lee, K., McLoughlin, A., Boggis, C., Sutton, A., et al. (2004). Interprofessional education in a midwifery curriculum: The learning through the exploration of the professional task project (LEAPT). Midwifery, 20, 358-366.

Gavin, K. (2009). Cultural incapacity and cultural blindness. Retrieved from https://wiki.gpaea. k12.ia.us/groups/cornerstone/wiki/56cb5/Cultural_Incapacity_and_Cultural_Blindness.html. Accessed May 2, 2016.

Ghaye, T. (2011). Teaching and learning through reflective practice: A practical guide for positive action. London \& New York: Routledge.

Griffiths, M. (1998). Educational research for social justice: Getting off the fence. Buckingham: Open University Press.

Hawthorne, K., Prout, H., Kinnersley, P., \& Houston, H. (2009). Evaluation of different delivery modes of an interactive e-learning program for teaching cultural diversity. Patient Education and Counseling, 74, 5-11.

Hayes, I., Enohumah, K., \& McCaul, C. (2011). Care of the migrant obstetric population. International Journal of Obstetric Anesthesia, 20, 321-329.

HEA. (2009). Effective learning and teaching in UK higher education. London: The Higher Education Academy, Teaching and Learning Research Program (TLRP).

HEA. (2011). The UK professional standards framework for teaching and supporting learning in higher education. London: The Higher Education Academy.

Healey, M., Flint, A., \& Harrington, K. (2014). Engagement through partnership: Students as partners in learning and teaching in higher education. London: The Higher Education Academy.

Hockings, C. (2010). Inclusive learning and teaching in higher education: A synthesis of research. London: The Higher Education Academy.

Hollinsworth, D. (2013). Forget cultural competence: Ask for an autobiography. Social Work Education, 32, 1048-1060.

Husbands, C., \& Pearce, J. (2012). What makes great pedagogy? Nine claims from research. Nottingham: National College for School Leadership.

Jenks, A. C. (2011). From "lists of traits" to "open-mindedness": Emerging issues in cultural competence education. Culture Medicine \& Psychiatry, 35, 209-235.

Kemmis, S., \& McTaggart, R. (Eds.). (1988). The action research planner. Geelong: Deakin University Press.

Kildea, S., Barclay, L., \& Brodie, P. (2006). Maternity care in the bush: Using the Internet to provide educational resources to isolated practitioners. Rural and Remote Health (Online), 6.

Kleiman, S., Frederickson, K., \& Lundy, T. (2004). Using an eclectic model to educate students about cultural influences on the nurse-patient relationship. Nursing Education Perspectives, 25, 249-253.

Kleinman, A., \& Benson, P. (2006). Anthropology in the clinic: The problem of cultural competency and how to fix it. PLoS Med, 3, e294/1673-1676.

Kline, R. (2014). The "snowy white peaks" of the NHS: A survey of discrimination in governance and leadership and the potential impact on patient care in London and England. Middlesex: Middlesex University Business School.

Kline, R. (2015). Beyond the snowy white peaks of the NHS? Better health briefing 39: A race equality foundation briefing paper. London: Race Equality Foundation.

Kolb, D. A. (1984). Experiential learning: Experience as the source of learning and development. Upper Saddle River, NJ: Prentice Hall.

Koshy, V. (2005). Action research for improving practice: A practical guide. London: Paul Chapman Publishing. 
Kripalani, S., Bussey-Jones, J., Katz, M. G., \& Genao, I. (2006). A prescription for cultural competence in medical education. Journal of General Internal Medicine, 21, 1116-1120

Larrivee, B. (2000). Transforming teaching practice: Becoming the critically reflective teacher. Reflective Practice, 1, 293-307.

Latif, S. (2010). Effective methods of engaging black and minority ethnic communities within health care settings. Better health briefing 18: A race equality foundation briefing paper. London: Race Equality Foundation.

Laveist, T. A., Relosa, R., \& Sawaya, N. (2008). The COA360: A tool for assessing the cultural competency of healthcare organizations. Journal of Healthcare Management, 53, 257-267.

Lavizzo-Mourey, R., \& MacKenzie, E. R. (1996). Cultural competence: Essential measurements of quality for managed care organizations. Annals of Internal Medicine, 124, 919-921.

Lenette, C. (2014). Teaching cultural diversity in first year human services and social work: The impetus for embedding a cultural safety framework. A practice report. The International Journal of the First Year in Higher Education, 5.

Levin, M., \& Greenwood, D. (2001). Pragmatic action research and the struggle to transform universities into learning communities. In P. Reason \& H. Bradbury (Eds.), Handbook of action research: Participative inquiry and practice. London: SAGE.

Lindsey, R. B., Nuri-Robins, K., \& Terrell, R. D. (Eds.). (2009). Cultural proficiency: A manual for school leaders (3rd ed.). Thousand Oaks, California: Corwin Press.

Lubinski, R., \& Matteliano, M. A. (2008). A guide to cultural competence in the curriculum: Speechlanguage pathology. New York: Center for International Rehabilitation Research Information and Exchange (CIRRIE).

Manske, G. (2009). Cultural destructiveness. Retrieved from https://wiki.gpaea.k12.ia.us/groups/ cornerstone/wiki/49c55/Cultural_Destructiveness.html. Accessed May 2, 2016.

McKee, L., West, M., Flin, R., Grant, A., \& Johnston, D. (2010). Understanding the dynamics of organisational culture change: Creating safe places for patients and staff. Aberdeen.

McKellar, L., Pincombe, J., \& Henderson, A. (2008). Enhancing fathers' educational experiences during the early postnatal period. Journal of Perinatal Education, 17, 12-20.

McKellar, L., Pincombe, J., \& Henderson, A. (2009). Encountering the culture of midwifery practice on the postnatal ward during action research: An impediment to change. Women \& Birth, 22, $112-118$.

McKellar, L. V., Pincombe, J., \& Henderson, A. M. (2002). Congratulations you're a mother: A strategy for enhancing postnatal education for first-time mothers investigated through an action research cycle. Journal of the Australian College of Midwives Inc., 15, 24-31.

McNiff, J. (2002). Action research for professional development: Concise advice for new action researchers. Dorset: September Books.

Mezirow, J. (1997). Transformative learning: Theory to practice. New Directions for Adult and Continuing Education, 5-12.

Michie, S., Van Stralen, M. M., \& West, R. (2011). The behaviour change wheel: A new method for characterising and designing behaviour change interventions. Implementation Science, 6, 1-11.

Miller, E., \& Green, A. R. (2007). Student reflections on learning cross-cultural skills through a "cultural competence" OSCE. Medical Teaching, 29, 76-84.

Miller, H. M. (2001). Teaching \& learning about cultural diversity: Becoming a multicultural teacher. The Reading Teacher, 55, 346-347.

Moon, J. A. (1999). Reflection in learning \& professional development: Theory \& practice. London $\&$ New York: Routledge Falmer.

Moore, J., Crozier, K., \& Kite, K. (2012). An action research approach for developing research and innovation in nursing and midwifery practice: Building research capacity in one NHS foundation trust. Nurse Education Today, 32, 39-45.

Mountford-Zimdars, A., Sabri, D., Moore, J., Sanders, J., Jones, S., \& Higham, L. (2015). Causes of differences in student outcomes. HEFCE: Report to HEFCE by King's College London, ARC network and the University of Manchester. 
MSH. (2008). The provider's guide to quality \& culture: Quality \& culture quiz. A joint project of Management Sciences for Health (MSH), U.S. Department of Health and Human Services, Health Resources and Services Administration, Bureau of Primary Health Care. Retrieved from https://erc.msh.org/.

Mulligan, J. (1993). Activating internal processes in experiential learning. In D. Boud, R. Cohen, \& D. Walker (Eds.), Using experience for learning. Buckingham: The Society for Research into Higher Education \& Open University Press.

Murray-Davis, B., Marshall, M., \& Gordon, F. (2011). What do midwives think about interprofessional working and learning? Midwifery, 27, 376-381.

Nairn, S., Hardy, C., Harling, M., Parumal, L., \& Narayanasamy, M. (2012). Diversity and ethnicity in nurse education: The perspective of nurse lecturers. Nurse Education Today, 32, 203-207.

Napier, A. D., Ancarno, C., Butler, B., Calabrese, J., Chater, A., Chatterjee, H., et al. (2014). Culture and health. The Lancet, 384, 1607-1639.

Nikbakht, N. A., Parsa, Y.Z., \& Barimnejad, L. (2005). Research development in Tehran Nursing and Midwifery School: An action research report. Hayat Journal of Faculty of Nursing \& Midwifery, $11,5-14$.

NMC. (2015). The code: Professional standards of practice and behaviour for nurses and midwives. London: The Nursing \& Midwifery Council (UK).

Noble, A., Engelhardt, K., Newsome-Wicks, M., \& Woloski-Wruble, A. C. (2009). Cultural competence and ethnic attitudes of midwives concerning Jewish couples. Journal of Obstetric, Gynecological \& Neonatal Nursing, 38, 544-555.

Norton, N. E. L., \& Bentley, C. C. (2006). Making the connection: Extending culturally responsive teaching through home(land) pedagogies. Feminist Teacher, 17, 52-70.

Nyman, V., Berg, M., Downe, S., \& Bondas, T. (2015). Insider action research as an approach and a method-Exploring institutional encounters from within a birthing context. Action Research, $0,1-17$.

Odora Hoppers, C. A. (Ed.). (2002). Indigenous knowledge and the integration of knowledge systems: Towards a philosophy of articulation. Claremont, South Africa: New Africa Books.

O'Leary, Z. (2004). The Essential Guide to Doing Research. London: Sage

Papadopoulos, I., Tilki, M., \& Ayling, S. (2008). Cultural competence in action for CAMHS: Development of a cultural competence assessment tool \& training program. Contemporary Nurse, $28,129-140$.

Pitkajarvi, M., Eriksson, E., \& Pitkala, K. (2013). Culturally diverse health care students' experiences with teaching strategies in Finland: A national survey. Nurse Education Today, 33, 590-595.

Ramsden, I. M. (2002). Cultural safety and nursing education in Aotearoa and Te Waipounamu. Doctor of Philosophy, Victoria University of Wellington.

RCM. (2015). Fear among midwives [The Birth Project Group]. Midwives Magazine, 60-62.

RCM. (2016a). BME midwives, disciplinary proceedings and the workplace race equality standard [Equality \& diversity publication]. London: The Royal College of Midwives.

RCM. (2016b). New findings raise spectre of discrimination against BME midwives in NHS. London: The Royal College of Midwives.

Reid, J. E. (2010). Impact of cultural competence educational learning unit intervention on firstsemester junior bachelor of science nursing students. Doctor of Education, St. John Fisher College.

Rocca-Ihenacho, L. (2016). An ethnographic study of the philosophy, culture and practice in a freestanding urban midwife-led unit [in progress] (Ph.D. presentation, City University London, London).

Ronnau, J. P. (1994). Teaching cultural competence: Practical ideas for social work educators. Journal of Multicultural Social Work, 3, 29-42.

Rutledge, C. M., Barham, P., Wiles, L., \& Benjamin, R. S. (2008). Integrative simulation: A novel approach to educating culturally competent nurses. Contemporary Nurse, 28, 119-128. 
Ryan, A., \& Tilbury, D. (2013). Flexible pedagogies: New pedagogical ideas. York: The Higher Education Academy.

Sandall, J., Coxon, K., MacKintosh, N., Rayment-Jones, H., Locock, L. \& Page, L. (2016). Relationships: The pathway to safe, high-quality maternity care [Sheila Kitzinger symposium summary report]. Oxford: Green Templeton College, Oxford.

Schön, D. A. (1991). The reflective practitioner: How professionals think in action. London: Ashgate.

Small, R., Liamputtong Rice, P., Yelland, J., \& Lumley, J. (1999). Mothers in a new country: The role of culture and communication in Vietnamese, Turkish and Filipino women's experiences of giving birth in Australia. Women and Health, 28, 77-101.

Smedley, B. D., Stith, A. Y., \& Nelson, A. R. (Eds.). (2003). Unequal treatment: Confronting racial and ethnic disparities in health care. Washington, DC

Smith, P., Masterson, A., Basford, L., Boddy, G., Costello, S., Marvell, G., et al. (2000). Action research: A suitable method for promoting change in nurse education. Nurse Education Today, $20,563-570$.

Smith, S., Gentleman, M., Loads, D., \& Pullin, S. (2014). An exploration of a restorative space: A creative approach to reflection for nurse lecturer's focused on experiences of compassion in the workplace. Nurse Education Today, 34, 1225-1231.

Sobel, D. M., \& Taylor, S. V. (2011). Culturally responsive pedagogy teaching like our students' lives matter. Bradford: BRILL.

Sreenivas, A., Cohen, S., Magana-Valladares, L., \& Walker, D. (2015). Humanized childbirth and cultural humility: Designing an online course for maternal health providers in limited-resource settings. International Journal of Childbirth, 5, 188-199.

Sutton, M. (2000). Improving patient care cultural competence: It's not just political correctness. It's good medicine. Family Practice Management, 7, 58-60.

Thackrah, R. D., \& Thompson, S. C. (2013). "Friendly racism" and white guilt: Midwidery students' engagement with Aboriginal content in their program. Forum on Public Policy, 1-12.

Torry, B. (2005). Transcultural competence in health care practice: The development of shared resources for practitioners. Practice, 17, 257-266.

Towle, A., Bainbridge, L., Godolphin, W., Katz, A., Kline, C., Lown, B., et al. (2010). Active patient involvement in the education of health professionals. Medical Education, 44, 64-74.

Tseng, W.-S., \& Streltzer, J. (2008). Cultural competence in health care: A guide for professionals. New York: Springer.

UNESCO. (2001). Universal declaration on cultural diversity. New York: UNESCO.

University of East London. (2015). Belong, believe, achieve: UEL strategy for closing the attainment gap. London: UEL.

Wadsworth, Y. (2001). The mirror, the magnifying glass, the compass and the map: Facilitating participatory action research. In P. Reason \& H. Bradbury (Eds.), Handbook of action research: Participative inquiry and practice. London: SAGE.

Wells, M. I. (2000). Beyond cultural competence: A model for individual and institutional cultural development. Journal of Community Health Nursing, 17, 189-199.

Wenger, E. (2012). Communities of practice and social learning systems: The career of a concept. Retrieved from https://wenger-trayner.com/wp-content/uploads/2012/01/09-10-27CoPs-and-systems-v2.01.pdf.

Wepa, D. (2003). An exploration of the experiences of cultural safety educators in New Zealand: An action research approach. Journal of Transcultural Nursing, 14, 339-348.

WHO. (2013). Midwifery educator core competencies. Geneva: The World Health Organisation.

Wikberg, A., \& Eriksson, K. (2008). Intercultural caring-An abductive model. Scandinavian Journal of the Caring Sciences, 22, 485-496.

Wikberg, A., Eriksson, K., \& Bondas, T. (2014). Immigrant new mothers in finnish maternity care: An ethnographic study of caring. International Journal of Childbirth, 4, 85-100.

Wilkins, C., Leamon, J., Rawnson, S., \& Brown, S. (2008). Student midwives' views of selfassessment. British Journal of Midwifery, 16, 88-94. 
Williamson, M., \& Harrison, L. (2010). Providing culturally appropriate care: A literature review. International Journal of Nursing Studies, 47, 761-769.

Wood, M. J., \& Atkins, M. (2006). Immersion in another culture: One strategy for increasing cultural competency. Journal of Cultural Diversity, 13, 50-54.

Penny Haora has worked in various capacities in diverse settings in the Asia Pacific Region and the United Kingdom. She completed a Ph.D. associated with a multidisciplinary Thailand Health Risk Transitions Study, based at the National Centre for Epidemiology and Population Health, Australian National University. Since 2001, Penny has been intermittently involved with evaluating health projects/services, mostly in remote areas of Nepal, Cambodia, and Afghanistan and recently has been evaluating a national-level midwifery education program in Bangladesh.

Open Access This chapter is licensed under the terms of the Creative Commons Attribution 4.0 International License (http://creativecommons.org/licenses/by/4.0/), which permits use, sharing, adaptation, distribution and reproduction in any medium or format, as long as you give appropriate credit to the original author(s) and the source, provide a link to the Creative Commons license and indicate if changes were made.

The images or other third party material in this chapter are included in the chapter's Creative Commons license, unless indicated otherwise in a credit line to the material. If material is not included in the chapter's Creative Commons license and your intended use is not permitted by statutory regulation or exceeds the permitted use, you will need to obtain permission directly from the copyright holder.

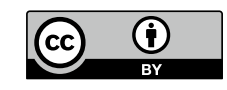

